\title{
IMPROVING PRACTICAL EXAMINATIONS IN SCIENCE
}

\section{SUBJECTS*}

\author{
R.H. Dave and Y.B. Patwardhan
}

National Institute of Education,

National Centre for Educational Research and Training, New Delhi, India.

Examination reform has now been accepted in our country as a very powerful instrument to improve quality in education. During the implementation of the reform programme particularly in science subjects it was felt that the work in these subjects would be incomplete unless the practical examinations are also reformed. In fact, the sixth conference of chairmen and secretaries of the boards of secondary education in the country held in November 1964 discussed at length the necessity of improving practical examinations and passed a resolution that the boards may take up this work in collaboration with the Central Examination Unit of the NCERT.

It was a source of great satisfaction that soon after this conference, the Board of Secondary Education, Rajasthan, came forward to take up the new venture in the field of examination reform. A series of experimental tryouts were carried out to evolve an improved system of practical examination and then the board implemented the new plan in its higher secondary examination of 1968 in the subjects of physics, chemistry and biology after making adequate preparation in collaboration with the NCERT. We give a brief résumé of the experimental studies conducted for the development of an improved pattern of practical examinations in science subjects and its large scale implementation.

\section{SHOR TCOMINGS OF THE PRESENT PATTERN}

A qualitative study based on verbal reports by a number of experienced examiners in Rajasthan revealed that the then existing pattern of examination suffered from the following major shortcomings:

1. Poor sampling: Each experiment given being very complex, comprehensive, and time consuming, only a few experiments (e.g., two in physics) could be set in the limited time available. As such it could only measure a small fragment of the content and a few of the many aspects of skill that practical work is expected to develop. This reduced both the validity and reliability of the practical examination. This was very discouraging to the pupil as well as to the teacher, especially on account of a high degree of chance factor operating in such a system.

2. Absence of reliable criteria of assessment: The criteria of assessment were very general and examiners were inclined to assess the performance of students according to varied standards leading to loss of consistency and uniformity.

* This article is reprinted, with permission from the NIE Journal, September 1969.

(Publication Unit, NIE Campus, Sri Aurobindo Marg, New Delhi 16, India). 
3. Non-comparability of exercises: The few exercises (e.g., two in physics) each pupil would get, varied very much in complexity and nature of skill involved. It was not justifiable to compare the performance of different candidates as obtained on the se differing instruments.

\section{BASES FOR A NEW PATTERN}

It was felt that practical tests are more costly and time-consuming, and so they should be used only when other more convenient techniques such as written tests cannot be used. It is in the realm of practical skills in the se subjects that written tests are not usable and hence practical tests shouId essentially be used to measure practical skill although other objectives such as knowledge, understanding or application need not be entirely eliminated. For this purpose practical skill was defined under the heads:

(a) process of performance, and

(b) product of performance.

They were further clarified in each subject to delimit their scope. In physics, for example, they were delimited as follows:

\section{Process of Performance}

The pupil

1. selects appropriate apparatus, tools, etc.

2. checks apparatus, tools, regarding their working.

3. detects errors and limitations in the fitting up of apparatus.

4. rectifies errors, if possible, under laboratory situation.

5. cleans apparatus, tools, etc.

6. sets up apparatus, tools, etc.

7. sketches arrangement of apparatus (if necessary, at the outset).

8. prepares and follows a systematic and sequential plan for taking observations.

9. states the principle, formula (explaining the symbols, etc., useful in the experiment).

10. manipulates apparatus, tools, etc:, while performing the experiment.

11. measures quantities and reads instruments, apparatus, etc., accurately.

12. takes precautions in handling instruments, substances, etc.

13. makes accurate observations of parts, specimens, processes, etc.

14. records observations and makes calculations where necessary.

15. verifies observations.

16. performs experiments with reasonable speed.

17. performs experiments with reasonable accuracy.

18. performs experiments with neatness.

19. adapts himself with somewhat new and different apparatus in setting novel experiments.

20 . explains orally the procedures, principles, etc., involved in the experiments. 
The pupil

1. summarizes observations.

2. calculates and finalizes the results.

3. interprets data and draws conclusions.

4. records experimental procedure and conclusions.

5. dismantles and cleans the apparatus, where necessary.

6. arranges the apparatus, substances, etc., at their

appropriate places at the end of the work.

\section{Sessional Practical Work}

The practical exercises performed by pupils in the higher secondary classes are recorded in specially developed record books. The skills and traits attained while performing the se may also be evaluated in board examinations. It may not be possible and also not desirable to evaluate all the traits developed, but a few like completeness, neatness and regularity may be evaluated with the assistance of the subject teacher. work are:

Some of the skills that may be appraised from this aspect of practical

1. Drawing diagrams and sketches from observed facts.

2. Collecting specimens like that of ores, minerals,

crystals, etc.

3. Displaying material collected.

4. Improvising simple apparatus.

5. Constructing moaess.

DEVELOPMENT OF A NEW PATTERN

For the purpose of improving validity and reliability the practical examinations were modified in the following respects:

1. Increasing the number of exercises: Instead of giving few Tong exercises, many short exercises are introduced, e.g., in physics one major comprehensive experiment is retained and the other is replaced by four or five short exercises. The maximum marks and the time, however, are kept the same.

2. Making the exercises objective-based: Exercises are to be set to test predetermined specific aspects of skill (or understanding) as laid down in the objectives. As mentioned earlier they include within the process and the product of performance. This tends to improve the validity of the practical examination.

3. Improving the sampling of abilities and content: Increase in the number of exercises enables the test to cover many different abilities as specified under the specifications of the skill objective and also to cover a variety of content areas. This helps in improving the coverage and consequently tends to improve reliability and validity.

4. Improving scoring procedures: Very detailed marking schemes giving minute analytical details of assessment of pupil performance are developed not only for major and short 
exercises but also for sessional work and viva. Detailed instructions are developed for the use of examiners and candidates for this purpose. This helps in improving objectivity of scoring and controlling inter-rater reliability by minimizing the variability in scoring by examiners emerging from extraneous factors like personal likes and dislikes.

5. Improving reporting and interpreting procedures:

Detailed proformas and instructions for their use are developed for the use of examiners. When these reports would be properly used by schools, they will be able to improve science teaching in many respects.

\section{TRY-OUTS}

Four examiners in each subjects of physics, chemistry and biology who were involved in the development of the new pattern tried out the se procedures three times in actual situation specially arranged for this purpose. In the first try-out 10 candidates and in the second and third try-outs 15 to 20 candidates were involved in all the three subjects. In all the try-outs the four examiners observed simultaneously and marked independently. The experience of earlier try-out was always invariably used to improve the exercises and refine the scoring schemes of the subsequent try-outs. The results of assessment were then studied and correlations found. The findings in the try-outs of biology are given here. In other subjects similar findings are available.

Comparative Study of Three Sets of Examiner Inter-correlations in Biology Practical Examination in Three Try-outs

A. Averaged across questions

\begin{tabular}{cccccccc}
\hline Examiner/Try-out & AB & AC & AD & BC & BD & CD & N \\
\hline I. & .78 & .65 & .67 & .83 & .74 & .68 & 12 \\
II. & .94 & .95 & .95 & .92 & .94 & .93 & 15 \\
III. & 1.00 & 1.00 & 1.00 & .99 & .99 & .99 & 15 \\
\hline
\end{tabular}

B. Based on total test scores

\begin{tabular}{cccccccc}
\hline Examiner/Try-out & $\mathrm{AB}$ & $\mathrm{AC}$ & $\mathrm{AD}$ & $\mathrm{BC}$ & $\mathrm{BD}$ & $\mathrm{CD}$ & $\mathrm{N}$ \\
\hline I. & .89 & .88 & .59 & .78 & .82 & .63 & 12 \\
II. & .87 & .45 & .84 & .55 & .90 & .45 & 15 \\
III. & .97 & .99 & .98 & .98 & .98 & .97 & 15 \\
\hline
\end{tabular}

$C$. Based on ranking of difficulty indices of questions

\begin{tabular}{cccccccc}
\hline Examiner/Try-out & AB & \multicolumn{1}{c}{ AC } & AD & BC & BD & CD & N \\
\hline I. & .88 & .90 & .90 & .98 & .78 & .75 & 9 \\
II. & .93 & 1.00 & .98 & .93 & .97 & .98 & 9 \\
III. & .98 & 1.00 & 1.00 & .98 & .98 & 1.00 & 9 \\
\hline
\end{tabular}




$$
\begin{aligned}
& \text { When } \mathrm{N}=9: .05=.600 ; .01=.783 \\
& \text { When } \mathrm{N}=12: .05=.506 ; .01=.712 \\
& \text { and When } \mathrm{N}=15: .05=.439 ; .01=.623
\end{aligned}
$$

In this subject, during the first try-out three out of six examiner inter-correlations are not significant at the .01 level but are significant at the .05 level. The agreement among the examiners in Try-out II is at or above .92. All the inter-correlations are substantially increased in Try-out II. Again, in Try-out III, the examiner inter-correlations averaged across the questions have reached unity in 3 out of 6 cases, and in the rest they are at .99. Thus the inter-examiner agreement in biology practical tests reached almost to the optimum as a result of intensive training, practice and development of well-designed scoring procedures.

\section{IMPLEMENTATION}

1. Preparation: Encouraged by the above findings, the Rajasthan Board decided to launch the reform programme on a large scale throughout the state. It, therefore, developed brochures in each subject entitled "Improved Pattern of Practical Examination" with the help of the NCERT and the examiners who participated in the try-outs, and circulated them to schools. The board also trained all examiners in new pattern of practical examination in the three science subjects. They were given training in the theory of conducting the examinations through four-day workshops organized for the purpose. They acquired practical experience in conducting the new type practical tests in actual examination, which were specially arranged at various places as a part of the training programme.

2. Implementation: With the se and other preparatory steps carefully executed, the board introduced the new pattern in the higher secondary examination of 1968 . Its impact on school practices is being closely watched. The preliminary review of the impact has been found to be quite encouraging.

\section{SOME PROBLEMS} envisaged.

During implementation some problems were faced which were already

1. Lack of equipped laboratories: Many schools do not have good laboratories. For want of such laboratories it becomes difficult to conduct the examination effectively. This applies to the old pattern of examination also.

Some laboratories do not have trained assistants. Services

of trained assistants are essential.

2. Number of candidates per examiner: This pattern envisages close observation of pupil performance during the period of examination. One examiner cannot obviously cope up with 20 candidates at a time as is the practice in vogue. Perhaps, 10 may be a manageable number.

3. Trained examiners: For some years, till the examiners are acquainted with the new pattern, it will have to be seen that every examiner is fully acquainted with the spirit and technique of the new pattern of examination before he is entrusted with the job. 
For the efficacy of this new examination co-operation from different agencies will be needed. Some implications to such agencies are indicated below :

Departments of Education and Boards of Secondary Education

1. School laboratories will have to be better equipped.

2. Practical syllabus may be reviewed.

3. Flexible time-tables will have to be permitted.

4. Better inspection and guidance programme will have

to be developed.

5. Only qualified and trained examiners will have to be selected.

6. Examiners' reports will have to be scrutinized and the

findings reported to schools for action.

Schools

1. More initiative on the part of individual teachers and pupils will be needed.

2. Rigidity of time-tables will have to be reduced.

3. Laboratories should be better equipped.

4. The evaluation data should be used for remediation and improvement.

Teachers

1. Variety of practical activities will have to be designed and organized to develop specific skills among pupils and to discourage the tendency of mechanical repetition of standard experiments.

2. Initiative on the part of pupils should be encouraged.

\section{CONCLUSION}

Practical work in science subjects is aimed at the realization of some specific purposes which cannot be otherwise achieved. Practical examinations, therefore, have to be so planned that they measure the degree of success achieved by practical work as a contribution towards the multifaced development of pupils' innate powers and subsequent achievements. The new pattern suggested here aims at this. It defines the outcomes of the process and the product of performance, stresses the need for developing valid and reliable tools of measurement and builds in ways to evaluate the results of measurement. It also envisages sound feedback procedures to utilize the results of evaluation in improving school practices. It is hoped that given a fair trial this pattern will work as a catalytic agent in making science education a dynamic process and a creative activity in our schools. 